\title{
The Promotion of News Editing Quality based on the Combination of Traditional Media and New Media
}

\author{
Huang Wenzhi ${ }^{1}$, Li Junpo ${ }^{2}$
}

1. Department of Humanities and Social Sciences, Zhangjiakou University, Zhangjiakou, Hebei, 075000, China

Key words: New media; Traditional media; News editing quality and ability; Ascension

\begin{abstract}
The current society has left Internet technology, and gradually improves our production and way of life. New media, based on Internet technology, is medium for today's rapid development, which had a larger impact on traditional media, and also put forward the new requirements of our News Editing Quality.
\end{abstract}

\section{INTRODUCTION}

With the development of the Times, new media and traditional media integration is the trend. In the process of fusion, there may be some difficulties, twists and turns, such as requiring higher quality and ability of news editors. News is mainly through images, language, and texts to achieve the purpose of the report, and its authenticity and appeal will be affected by news editors' ability. In order to improve news broadcast effect, news editorial staff quality and ability should be improved. According to working experience, the author thinks that under the combination of new media and traditional media, News Editing Quality and ability ascension should be from editing style, news angle, different ranks, difference situation, emotions choice, skill choice, and professional ethics, etc.

\section{TRADITIONAL MEDIA REFORM AND NEW MEDIA INTEGRATION}

With the further popularization of the Internet and the rapid development of smart phone technology, new media have achieved amazing leap no matter from quantity or scale. According to statistics, by 2014, China's Internet users have reached 670 million people, and according to development trend, the number of Internet use in China will be more than 800 million in 2015. Also we can see the status and the importance of new media in media industry. Traditional media have to change the operation mode, combined with the experience of new media, and integrate new media development.

\section{A. Establish a comprehensive and multi-level media system}

New media is not restricted by the spread means and forms of information, and can exchange information and communicate through mobile phones, TV, computer and other multiple clients, and the contents of the transmission contain text, images, sound, video and other media forms. Emerging media will also be able to integrate all aspects of the media industry effectively. Whether it's dominated by the government or private businesses, it can be on the same platform to show the audience. The emerging media content is richer and contains all kinds of daily events, culture, sports, and military hot spots that people need to know, and can provide a series of professional knowledge according to the needs of users, such as medical, architecture, literature and so on. It really meets universal coverage of user needs knowledge. By drawing on the successful experience of new media, traditional media can restructure and perfect its original system to provide more abundant information for the audience.

\section{$B$. The complementary advantages of information resources realize}

Thanks to the rapid development of emerging media, new media industry capital and technology have been enhanced, which is more conducive to the further integration of information system. Some emerging media set up information transmission network with distinct features by learning and integration of traditional media, and promote common development and progress of new media and traditional media. New media has the advantages of fast transmission speed and diversified information and can satisfy the audience's information demand. Traditional media can achieve internal reform unceasingly with the development of new media advantage, docks with the new 
media, studies new media development experience and advantage, and improves the competitive position of traditional media in the market. For instance, the current national focus development of "three nets into one" is to merge information dissemination channels, and promote the development of information dissemination. Some traditional newspapers and radio stations are also actively developing their own mobile phone or computer client to further expand their audience.

C. The rising influence

With the continuous expansion of emerging media, the application of emerging media is becoming more and more popular among people's life. The current application of We Chat, Micro blog, or network BBS is not only confined to young people. And the influence of new media is not only in terms of entertainment, but can be a tool for some public opinion polls because of the convenient information sharing and communication. A lot of TV shows have added Micro blog attention as an important standard to evaluate the popularity. And some government departments can also through new media to get people's attitudes and opinions on events, and adjust their policies in a timely manner. New media has entered an unprecedented stage of development. Facing the impact of new media, traditional media has to carve out a new innovative development path, and win the audience with new forms and rich contents. At present, mobile news subscription is popular, which also is a breakthrough of traditional media in the new era, and represents the fusion of traditional media and new media. Both promote the development of media industry in our country.

\section{THE EXPLORATION OF HOW TO PROMOTE THE QUALITY OF NEWS EDITING ABILITY BASED ON TRADITIONAL MEDIA AND NEW MEDIA}

\section{A. News editing style control}

Before news editing, establish the picture editing style in line with new media. According to the different content of manuscripts and raw material, choose to adapt them to television news editing style, and then develop TV news footage clips according to the arrangement of news structure, material selection, and arrangement order. In the process of editing, ensure that it has the same technical style before and after editing, and ensure that clips of news picture subject conform to the requirements of the broadcast. Particularly TV news picture is applicable to many stories and ensure that the fixed style is throughout the clip [1].

B. Grasp news angles

At the scene of actual interview, on-site environmental uncertainty, filming location randomness, range metropolitan shoot a series of influence to the reporter, and there is interference by the heavy camera, so the reporter will make a preliminary screening, that is to say the TV news footage we received is not the whole picture. Lens are more in chaos, leading to TV news footage things, and tasks more complex, and editing work is to find the best fit picture and edit news subject. This is a very important process, which relates to the ultimate effect of TV news footage clips [2]. Also only in this way could associate people and things in the picture with different size, density, high and low, light and shade with the subject of the news, and explain and interpret to form one of the most suitable angle for the audience to understand the news, and quick and easy to understand the content of the news broadcast.

\section{Enhance situation difference discrimination}

Each TV news item adopts different shooting skills, including skills like pull, move, shake, and the picture is composed of multiple shots, including close shot, panoramic view, close-up, middle picture. In actual process, only by using different shooting skills can we shoot out a good TV news footage. In order to ensure the picture structure have stereo feeling, and with smooth flowing, editing workers should choose different scenes and shooting skills, and try different combinations, find the best combination of images, and pay attention to the rationality of the lens. At the same time, the picture must conform to the audience's visual and thinking, language habits, and let the audience experience the good pictures. In general, a panoramic view and vision scene are aimed to introduce the comprehensive development of news site and surrounding environment; Middle scene is primarily to describe specific things; Features and close shot scene mainly applies colors to a drawing atmosphere, and describes the details of the picture; Follow, pull, move, shake and other 
camera skill are mainly used in order to fully display the running process of things effectively and the main characteristics. Non speaking or independent lens clips need to make editing work on the basis of grasping the essence and core, use correct editing rule, select suitable picture to clip, and make different scenes composition to be a talking video. Ensure that the final cut picture is fluent and conforms to the understanding of the audience. At the same time, be bold to abandon low standard degree, deviating from the theme lens. Strive to be concise to improve the sense of perspective on the basis of clear news events.

D. Improve the rationality of selecting moods

The characters in TV news footage often show emotions such as happy, sad, angry, and ashamed. These are an important part of TV news footage, so in the process it will be difficult to choose, even appear inappropriate cuts affecting the authenticity of television news, and make news broadcast accidents. So when cut people mood clips on TV news footage, first of all, on the basis of the specific site, people and things, carry on preliminary, and then according to the characters in the news, specifically edit scene atmosphere, and environmental factors to guarantee ultimate cuts perfect fit the needs of the news reports.

E. Improve the accuracy of background selection

Each section of TV news footage has its specific object and background. Object generally refers to people or objects, and objects have different development process in the background. So the choice of background must have high authenticity, or the audience is easy to doubt the truth of the whole news footage [3]. After concrete lens are taken out, their objects, backgrounds and scenes are different, so when make TV news footage clips, it is important to note the change of the lens, the object and background, understand the inner link between them, make the final image-editing strong and persuasive, then foil theme, express the theme, and prominent theme.

F. Improve appropriateness of skills choice

Lens using cameras filming technique performance and photograph are the most original TV news footage and most valuable materials. Although due to the limitations of cameras filming technique performance, procrastination of some footage will be produced, but its authenticity cannot be ignored. It is with a strong appeal and has more persuasion. In the process of editing, shear on the basis of reality as far as possible not to undermine the appeal of the lens, and give full play to their positive role. As the speeding up of people life rhythm, people are keener on "slice" lens. So they can both accept the time used to browse the video, and have enough information. One of the features of "cut" is fast, which is more in line with the rhythm of the whole society, and "cut" has more strong expressive force, so the current TV news editing uses more "slice". Technique choice is closely related to news topic, so when choosing techniques to analyze the theme, and combining with the scene, speed and length of lens, determine the final editing skills.

G. Improve professional ethics alignment

Different industries have different ethical requirements. For news editors, authenticity is the most important news editor ethical requirements. Real is the lifeline of news. Lost reality, the news will lose the meaning of existence. From the perspective of journalism, "true" and "news" should be organically unified together [4-5]. If lack "true", news is pale, even boring. News value is achieved through the external object, and news only has authenticity to realize its social value. In addition to the "true", news should also guide society to the development of "good" and "beauty", which is professional moral requirement of news editors, especially party newspaper news editors. No "evil" and no "ugly" news, report more meaningful and positive energy news, and give full play to the role of party newspaper public opinion direction. News editors should strictly abide by professional ethics requirements.

\section{Conclusion}

With the further development of network technology, the social influence of new media will be further enhanced, and news editors should conform to the development of The Times, fully realize their own development difficulties. Step by step, improve the comprehensive quality to adapt to the development of media culture, the change of transmission mode, and provide talent base for report 
model, business process, and the optimization and perfection of spreading.

\section{REFERENCES}

[1] Gao Qiyang. News editing quality thinking under the new media and traditional media [J]. Journal of News Study Tribune, 2015, (8) : 65-65 nominal.

[2] Qiao Yong. News editors how to transform under the new media era [J]. Journal of News Study Tribune, 2015, (9) : 75-75120.

[3] Meng Xianguo. Introduction to China's traditional media news editor transformation under the background of media convergence [J]. Science and Technology Innovation Herald, 2014, (27) : 202-202.

[4] Li Yaqiang. Introduction to some of the key factors in the shooting TV news [J]. Journal of Youth, 2013, (15) : 161.

[5] Nie Chenxi. Set up the fusion between radio traditional media and new media integration----thoroughly study and apply the important instruction of Xi Jinping comrade about media fusion [J]. Journal of Broadcasting and Television Technology, 2014, 12, 16 and $18+10+$ 14. 